\title{
Biomimetic Apatite Formation on Different Polymeric Microspheres Modified with Calcium Silicate Solutions
}

\author{
I.B. Leonor ${ }^{1,2,3}$, F. Balas ${ }^{4}$, M. Kawashita ${ }^{3}$, R.L. Reis ${ }^{1,2}$, T. Kokubo ${ }^{4}$, T. \\ Nakamura ${ }^{5}$ \\ ${ }^{1} 3$ Bs Research Group - Biomaterials, Biodegradables and Biomimetics, Univ. of Minho, Campus de \\ Gualtar, 4710-057 Braga, Portugal \\ ${ }^{2}$ Depart. of Polymer Engineering, Univ. of Minho, Campus de Azurem, 4800-058 Guimarães, \\ Portugal \\ ${ }^{3}$ Ion Beam Engineering Experimental Laboratory, Graduate School of Eng. Kyoto Univ., Kyoto \\ 615-8510, Japan \\ ${ }^{4}$ Institute of Science and Technology Research, Chubu Univ., Aichi 487-8501 Japan \\ ${ }^{5}$ Depart. of Orthopaedic Surgery, Graduate School of Med., Kyoto Univ., Kyoto 606-8507, Japan \\ abelinha@dep.uminho.pt
}

Keywords: apatite, biomimetic process, polymeric microspheres, silanol groups, sol-gel.

\begin{abstract}
Bioactive polymeric microspheres can be produced by pre-coating them with a calcium silicate solution and the subsequent soaking in a simulated body fluid (SBF). Such combination should allow for the development of bioactive microspheres for several applications in the medical field including tissue engineering. In this work, three types of polymeric microspheres with different sizes were used: (i) ethylene-vinyl alcohol co-polymer $(20-30 \mu \mathrm{m})$, (ii) polyamide $12(10-30 \mu \mathrm{m})$ and (iii) polyamide $12(300 \mu \mathrm{m})$. These microspheres were soaked in a calcium silicate solution at $36.5^{\circ} \mathrm{C}$ for different periods of time under several conditions. Afterwards, they were dried in air at $100^{\circ} \mathrm{C}$ for $24 \mathrm{hrs}$. Then, the samples were soaked in SBF for 1, 3 and 7 days. Fourier transformed infrared spectroscopy, thin-film X-ray diffraction, and scanning electron microscopy showed that after the calcium silicate treatment and the subsequent soaking in SBF, the microspheres successfully formed a bonelike apatite layer on their surfaces in SBF within 7 days due to the formation of silanol (Si-OH) groups that are quite effective for apatite formation.
\end{abstract}

\section{Introduction}

Biodegradable polymeric microspheres are used for several applications in the biomedical field, namely as carriers of biologically active agents. Furthermore, it is believed that the use of microspheres can lead to more versatile applications in bone repair and might be useful for designing injectable biomaterial systems. When developing new biomaterials for bone regeneration, surface properties must be modulated, ideally in order to mimic the tissue to be replaced. Furthermore, a strong bonding between the host bone and the osteoconductive surface is required. It has been reported that silanol $(\mathrm{Si}-\mathrm{OH})$ groups on polymeric materials can induce apatite formation in acellular simulated body fluids (SBF) with ion concentrations nearly equal to those of the human blood plasma [1-3]. Also, it was demonstrated that when an ethylene-vinyl alcohol co-polymer (EVOH) was treated with silane coupling agent and calcium silicate solution and then soaked in SBF a smooth and uniform bonelike apatite layer was able to be formed on the surface of $\mathrm{EVOH}$ [4]. The aim of this study is to incorporate $\mathrm{Si}-\mathrm{OH}$ groups onto polymeric microspheres by soaking them in a calcium silicate solution, in order to obtain bioactive microspheres for bone repair that are able to in situ release an antibiotic for treatment and prevention of bone infection. 


\section{Materials \& Methods}

Three types of microspheres with different sizes were used as substrates: (i) ethylene-vinyl alcohol co-polymer (EVOH; 20-30 $\mu \mathrm{m}$ ), (ii) polyamide 12 (PA 12; 10-30 $\mu \mathrm{m}$ ), (iii) polyamide 12 (PA 12; 300 $\mu \mathrm{m})$. These microspheres were kindly supplied by Trial Corporation, Japan. Tetraethoxysilane (TEOS: $\left.\mathrm{Si}\left(\mathrm{OC}_{2} \mathrm{H}_{5}\right)_{4}\right)$, ultra-pure water, ethyl alcohol $\left(\mathrm{C}_{2} \mathrm{H}_{5} \mathrm{OH}\right), 1.0 \mathrm{M}-\mathrm{HCl}$ aqueous solution and calcium chloride $\left(\mathrm{CaCl}_{2}\right)$ were mixed for $10 \mathrm{~min}$ at $0^{\circ} \mathrm{C}$ in order to prepare calcium silicate solution with a molar ratio of TEOS / $\mathrm{H}_{2} \mathrm{O} / \mathrm{C}_{2} \mathrm{H}_{5} \mathrm{OH} / \mathrm{HCl} / \mathrm{CaCl}_{2}$ of $1.0 / 4.0$ or $2.0 / 4.0$ or 1.0/ 0.014 / 0.20. The microspheres were immediately soaked in $10 \mathrm{ml}$ of calcium silicate solution with $\mathrm{H}_{2} \mathrm{O} / \mathrm{TEOS}=4 / 1$ at $36.5^{\circ} \mathrm{C}$ and $120 \mathrm{rpm}$ for $2 \mathrm{hrs}$ (condition I) and soaked for $5 \mathrm{~min}$ in a calcium silicate solution with $\mathrm{H}_{2} \mathrm{O} / \mathrm{TEOS}=2 / 1$ prepared $168 \mathrm{hrs}$ before (condition II). The specimen were filtered and then dried in air at $100^{\circ} \mathrm{C}$ for $24 \mathrm{~h}$. Then, the specimens were soaked in $20 \mathrm{ml}$ of SBF [1] with ion concentrations $\left(\mathrm{Na}^{+} 142.0, \mathrm{~K}^{+} 5.0, \mathrm{Ca}^{2+} 2.5, \mathrm{Mg}^{2+} 1.5, \mathrm{Cl}^{-} 147.8, \mathrm{HCO}_{3}^{-}\right.$4.2, $\mathrm{HPO}_{4}{ }^{2-}$ 1.0, $\mathrm{SO}_{4}{ }^{2-} 0.5 \mathrm{mM}$ ) nearly equal to those of the human blood plasma at $36.5^{\circ} \mathrm{C}$ and $\mathrm{pH}=7.40$ for several periods up to 7 days. The specimens were analysed by field-emission scanning electron microscopy (FE-SEM) with an attached energy dispersive electron probe X-ray analyser (EDS), thin-film X-ray diffraction (TF-XRD), and Fourier transform infrared attenuated total reflection spectroscopy (FT-IR). The concentrations of $\mathrm{Si}, \mathrm{Ca}$, and $\mathrm{P}$ in the $\mathrm{SBF}$ solution were measured by inductively coupled plasma atomic emission spectroscopy (ICP) as a function of the immersion time.

\section{Results}

For both conditions, all the investigated microspheres could be successfully coated with a calcium silicate layer. After the calcium silicate treatment, the reflection peaks of hydroxyl $(-\mathrm{OH})$ and silanol (Si-OH) groups, which are typically observed for a silica gel, and $\mathrm{Si}-\mathrm{O}-\mathrm{Si}$ bond were detected in the FT-IR spectra. The presence of Si-OH groups and Si-O-Si bond suggests that TEOS was successfully hydrolyzed to form $\mathrm{Si}-\mathrm{OH}$ groups and polycondensed to form Si-O-Si network. The intensity of $\mathrm{Si}-\mathrm{OH}$ peak was more pronounced for condition II than condition I.

Figure 1 shows TF-XRD patterns of the surfaces of PA $12(300 \mu \mathrm{m})$ and PA $12(10-30 \mu \mathrm{m})$ microspheres, which were coated with a calcium silicate layer under condition I or II and subsequently soaked in SBF up to 7 days.
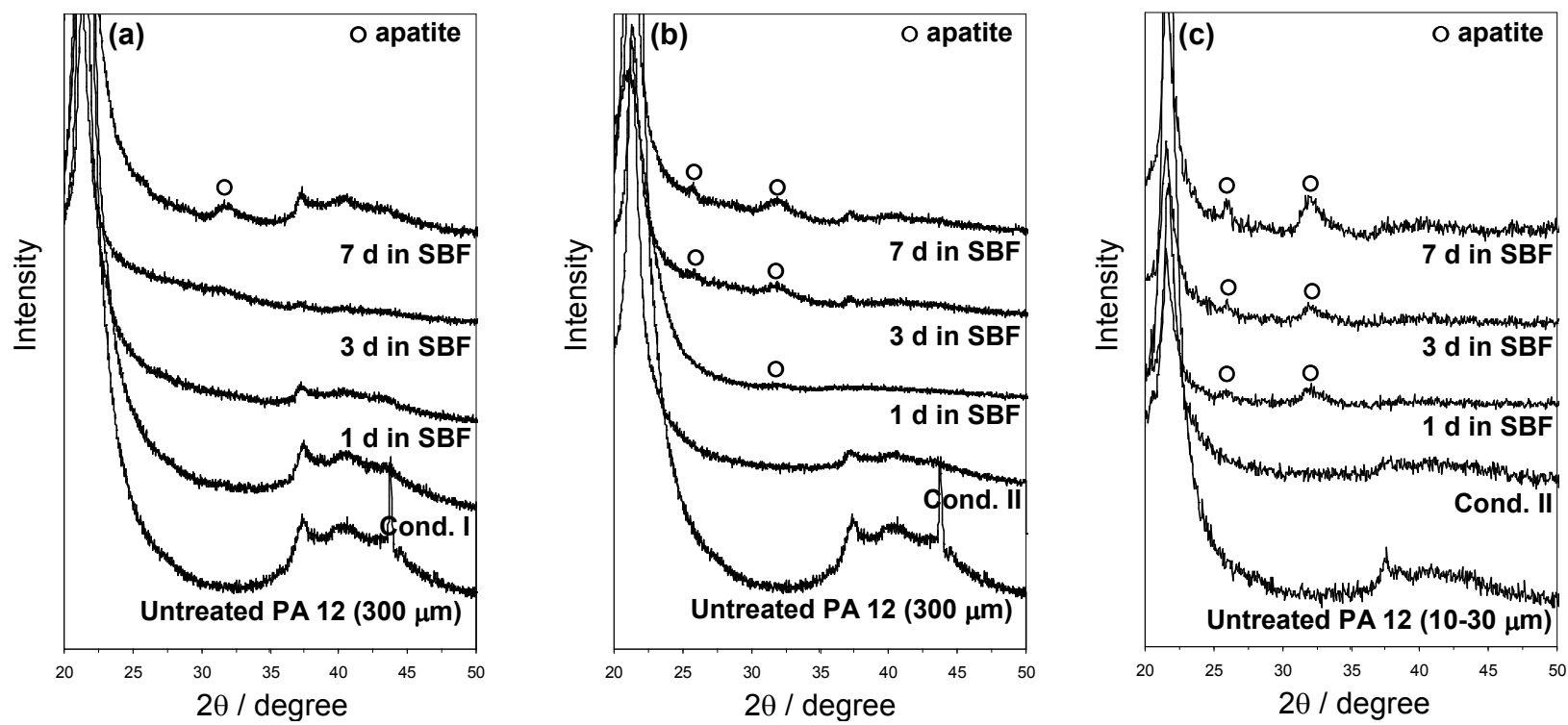

Figure 1. TF-XRD patterns of the surfaces of PA $12(300 \mu \mathrm{m})$ and PA $12(10-30 \mu \mathrm{m})$ microspheres, which were coated with a calcium silicate layer under condition I or II and subsequently soaked in SBF for 1, 3 and 7 days. 
For both conditions I and II, the structure of all microspheres was not changed even after the coating, giving the same diffraction patterns as the untreated microspheres. After soaking in SBF for several periods, the TF-XRD patterns showed several diffraction maxima that can be assigned to an apatite-like phase (ASTM JCPDS 9-432). For condition II, all the investigated microspheres showed an ability to induce the formation of an apatite layer within 1 day in SBF (See the Figs. 1-(b) and 1-(c)). However, for condition I, only the microspheres PA $12(300 \mu \mathrm{m})$ formed an apatite layer after 7 days in SBF, as shown in Fig. 1-(a). These differences might be attributed to a further progress of hydrolysis and polycondensation of TEOS in the calcium silicate solution due to a long aging period such as $168 \mathrm{hrs}$ in condition II. The intensities of apatite peaks increased with increasing soaking time, which indicates the growth of the apatite layer in SBF.

Figure 2 shows FE-SEM images of the surfaces of PA $12(300 \mu \mathrm{m})$ and PA $12(10-30 \mu \mathrm{m})$ microspheres before and after the calcium silicate treatment under condition I or II and subsequent soaking in SBF up to 7 days.

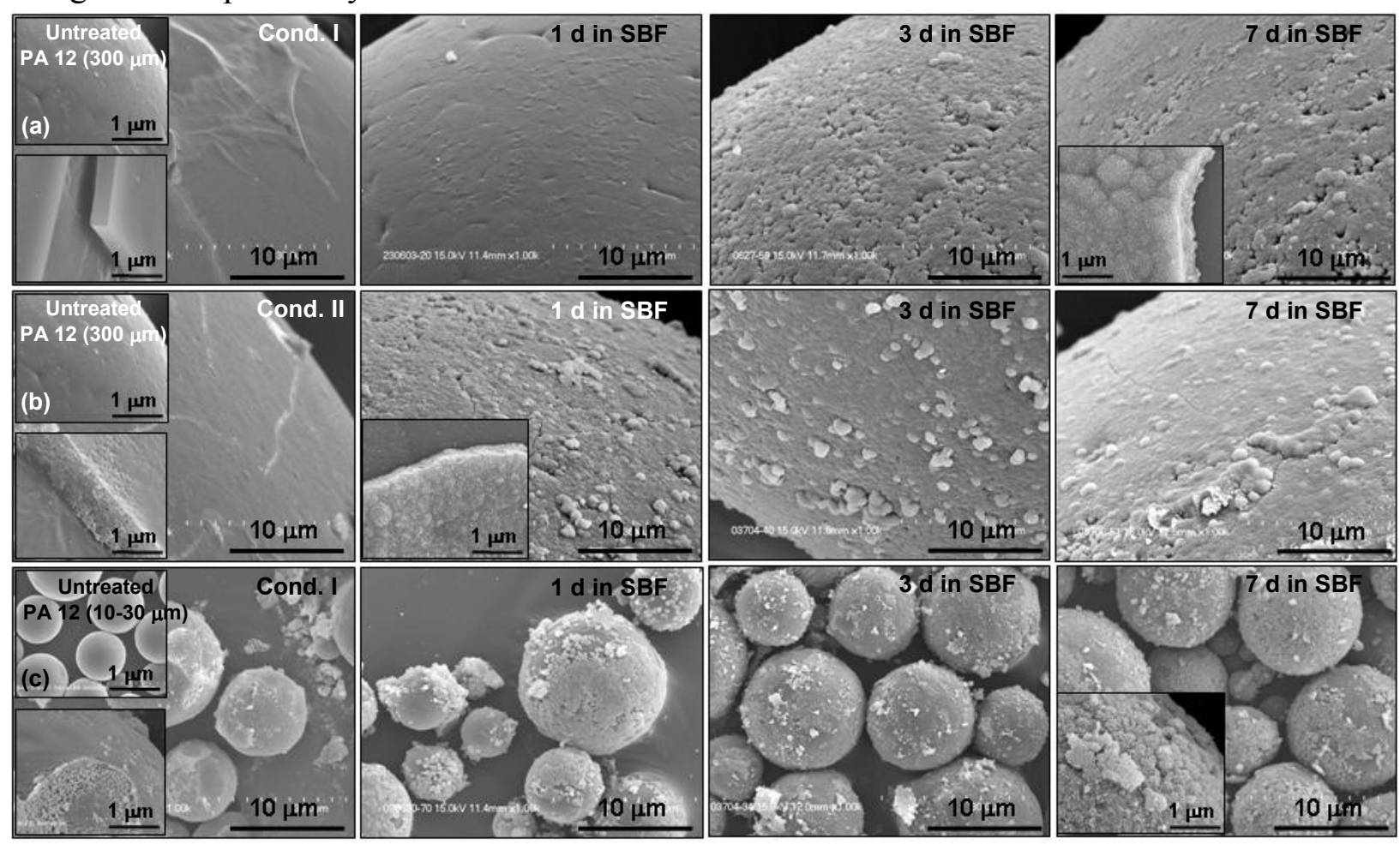

Figure 2. FE-SEM images of the surfaces of PA $12(300 \mu \mathrm{m})$ and PA $12(10-30 \mu \mathrm{m})$ microspheres before and after the calcium silicate treatment under condition I or II and subsequent soaking in SBF for 1, 3 and 7 days.

For condition I, the microspheres PA $12(300 \mu \mathrm{m})$ were completely covered with a uniform apatite layer after 3 days (Fig. 2-(a)). However, this layer was very fine and not dense, which was in agreement with the TF-XRD in Fig. 1-(a). In contrast, when the microspheres PA $12(10-30 \mu \mathrm{m})$ and PA $12(300 \mu \mathrm{m})$ were treated with a calcium silicate solution under condition II, all the microspheres were completely covered with a uniform apatite layer within 1 day in SBF as shown in the Figs. 2-(b) and (c). This layer had a finer structure, where needle-like crystals were agglomerated. However, in the case of PA $12(10-30 \mu \mathrm{m})$, the apatite layer was not as dense as for PA $12(300 \mu \mathrm{m})$ (See Figs. 2-(b) and (c)). For EVOH (20-30 $\mu \mathrm{m})$, the formation of an apatite layer was observed after the calcium silicate treatment in condition II and the subsequent soaking in SBF for 1 day. However, an aggregation of these microspheres was found to occur quite easily both in a calcium silicate solution as well as in SBF.

By EDS measurement, an appreciable quantity of $\mathrm{Ca}$ and $\mathrm{P}$ was detected on the surface of the PA $12(300 \mu \mathrm{m})$ microspheres after the calcium silicate treated under the condition $\mathbf{I}$ and subsequent 
soaking in SBF for 3 days and, in the case of the condition II, it was after 1 day in SBF. For PA 12 $(10-30 \mu \mathrm{m})$ microspheres treated with a calcium silicate solution under condition II, the signal of the $\mathrm{Ca}$ and $\mathrm{P}$ elements was detected after 1 day in SBF, although its intensity was not as high as for PA 12 $(300 \mu \mathrm{m})$. From the EDS and FT-IR results, it was found that a calcium silicate layer, rich in Ca ions and $\mathrm{Si}-\mathrm{OH}$ groups, was formed on all the microspheres. However, the intensity of Si signal was larger for the condition II than for the condition $\mathbf{I}$.

By ICP analysis, for the condition II, a decrease in Ca and P concentrations and an appreciable increase in Si concentration were observed. The decrease in the $\mathrm{Ca}$ and $\mathrm{P}$ concentration is attributed to the formation of an apatite layer by consuming the $\mathrm{Ca}$ and $\mathrm{P}$ ion from the surrounding fluid. The increase in the Si concentration is attributed to the dissolution of silicate ions from the calcium silicate layer, which results in a formation of the $\mathrm{Si}-\mathrm{OH}$ groups. These groups are responsible for the apatite nucleation. The amount of these groups can be speculated by the rate of the dissolution of the silica into the SBF, because the dissolution of the silica gel, in this case calcium silicate gel, proceeds via hydrolysis of the silica [2-3].

\section{Discussion and Conclusions}

It was shown that a calcium silicate layer, rich in $\mathrm{Ca}$ ions and $\mathrm{Si}-\mathrm{OH}$ groups, was able to be formed on the microspheres by the present method and has the ability to induce the formation of a bone-like apatite layer. When the calcium silicate-coated microspheres were soaked in SBF, the Ca ions in the calcium silicate layer were released into SBF to form many Si-OH groups and simultaneously increased the ionic activity product of the surrounding fluid with respect to apatite. The Si-OH groups induced the apatite nucleation, and the increased ionic activity product accelerates the nucleation rate of apatite.

It is noted that there is a compositional difference between the two conditions. Namely, molar ratios of $\mathrm{H}_{2} \mathrm{O}$ /TEOS in condition I and condition II were $4 / 1$ and $2 / 1$, respectively. When the $\mathrm{H}_{2} \mathrm{O}$ /TEOS molar ratio of the calcium silicate solution is decreased, the time for gelation decreases [5]. As consequence, the calcium silicate solution in condition II gives a higher viscosity to form a uniform calcium silicate layer on the surfaces of the microspheres. Also, the calcium silicate layer obtained in condition II had a more porous structure than that in condition I (See the Figs. 2-(b) and (a)). It has been demonstrated that the porous structure in the silica gels can be related to the apatite nucleation [6-8]. The calcium silicate layer formed in condition II dissolved into SBF more rapidly than that formed in condition $\mathbf{I}$, and hence the induction time for apatite formation is reduced.

The resultant microspheres with apatite-forming ability are a very promising material to be used in the bone repair and regeneration field. This work is one of the first reports on the coating of microspheres with biomimetic calcium-phosphate layers.

\section{Acknowledgments}

I. B. Leonor thanks the Portuguese Foundation for Science and Technology (FCT) for providing her a PhD scholarship (SFRH / BD / $9031 / 2002$ ) and the European Union funded STREP Project HIPPOCRATES (NMP3-CT-2003-505758) and the European NoE EXPERTISSUES (NMP3-CT-2004-500283).

\section{References}

1. T. Kokubo, H. Kushitani, S. Sakka, T. Kitsugi, T. Yamamuro. J. Biomed. Mater. Res. 24 (1990): 721.

2. P. Li, X. Ye, I. Kangasniemi, J. M. A. de Blieck-Hogervorst, C. P. A. Klein, K. de Groot. J. Biomed. Mater. Res. 29 (1995): 325.

3. P. Li, C. Ohtsuki, T. Kokubo, K. Nakanishi, N. Soga, T. Nakamura, T. Yamamuro. J. Mat. Sci.: Mat. Med. 4 (1993): 127.

4. A. Oyane, M. Kawashita, K. Nakanishi, T. Kokubo, M. Minoda, T. Miyamoto, T. Nakamura. Biomaterials 24 (2003): 1729.

5. C. J. Brinker, G. W. Scherer: Sol-Gel Science-The Physcis and Chemistry of Sol-Gel Processing (Academic Press, Inc., San Diego 1990).

6. S. B. Cho, K. Nakanishi, T. Kokubo, K. Nakanishi, N. Soga, C. Ohtsuki, T. Nakamura. J. Biomed. Mater. Res. (Appl. Biomat.) 33 (1996): 145.

7. S. B. Cho, F. Miyaji, T. Kokubo, K. Nakanishi, N. Soga, T. Nakamura. J. Mat. Sci.: Mat. Med. 9 (1998): 279.

8. M. M. Pereira, A. E. Clark, L. L. Hench. J. Am. Ceram. Soc. 78 (9) (1995): 2463. 